\title{
Automação de bibliotecas e centros de documentação: 0 processo de avaliação e seleção de softwares
}

\section{Adelaide Ramos e Côrte lêda Muniz de Almeida Ana Emília Pellegrini Ildeu Ordini Lopes José Carlos Saenger} Maria Bernadete P. Esmeraldo Maria Cristina Moraes Pereira Rosana Rika M. C. Ferreira Wilma Garrido do Lago

\section{Resumo \\ O mercado de produção e geração de softwares para automação de bibliotecas apresentou grande impulso nos últimos dez anos. Escolher um software representa, hoje, mais que escolher uma ferramenta tecnológica para implementar serviços prestados pelas bibliotecas. Representa introduzir nova filosofia de trabalho, novos comportamentos e valores informacionais. Este trabalho apresenta o resultado dos estudos realizados para a escolha de um software para a automação das bibliotecas da Presidência da República. Pretende contribuir com a revisão de literatura e com os profissionais e estudiosos da área, oferecendo uma análise de cada produto, bem como a identificação dos requisitos indispensáveis e desejáveis que o software deve possuir para o processo de automação de bibliotecas e centros de documentação.}

\section{Palavras-chave}

Automação de bibliotecas; Softwares para bibliotecas; Informática aplicada a bibliotecas.

\section{INTRODUÇÃO}

As mudanças advindas com a sociedade da informação provocaram substanciais alterações nos hábitos de uso da informação no dia-a-dia do cidadão brasileiro, quer na sua vida pessoal, quer no desenvolvimento de sua carreira profissional, impulsionando as organizações para a busca de um processo de modernização de suas estruturas e maior agilidade na prestação de serviços à comunidade usuária.

As bibliotecas e centros de documentação, como unidades organizacionais vivas, recebem interferência diária em seus processos de trabalho, o que torna imprescindível a adequação de suas estruturas organizacionais e de prestação de serviços à então propalada sociedade da informação.

Especificamente no caso do processo de informatização, os avanços tecnológicos associados às exigências atuais dos usuários direcionam para a seleção e aquisição de software e hardware com características funcionalmente mais diversificadas, privilegiando a interligação das funções de uma biblioteca, numa linguagem que permita a integração usuário/máquina.

Atentos a essa situação e ao compromisso de oferecer aos seus usuários um serviço de qualidade, profissionais bibliotecários e analistas de sistemas da Presidência da República realizaram este estudo, em um esforço conjunto e fundamentados pela orientação e diretriz da então Diretoria Geral de Administração com vistas a modernizar os processos de trabalho das unidades organizacionais da Presidência. Cumpriu-se também o estabelecido no
Planejamento Estratégico de 1995, que incluía o projeto de informatização de suas rotinas, produtos e serviços, oferecendo à direção daquela instituição subsídios para a seleção de um software capaz de automatizar os processos de trabalho de suas bibliotecas.

Este artigo pretende, assim, apresentar as etapas necessárias ao processo de escolha de softwares, identificando os requisitos necessários à avaliação, caracterizando-os como gerais e específicos, imprescindíveis e desejáveis que devem ser contemplados pelos produtos disponíveis no mercado. Pretende, ainda, contribuir com a literatura na área e apresentar aos profissionais e estudiosos, uma experiência concreta de análise e seleção de software para bibliotecas e centros de documentação.

Os dados obtidos que fundamentaram este artigo remontam a abril de 1998, sendo importante registrar que, quando da publicação deste trabalho, certamente muitas alterações já terão acontecido nos produtos aqui descritos, como reação normal do mercado.

\section{REVISÃO DE LITERATURA}

A equipe decidiu que, para subsidiar este trabalho, deveriam ser identificados, na literatura, os softwares disponíveis no mercado e, principalmente, os impactos causados nos usuários, gerentes e técnicos dos serviços de informação bibliográfica, quando do processo de implantação da automação.

Com relação aos produtos existentes no mercado e na falta de catálogos que indicassem com certa abrangência 
este tipo de software, as informações obtidas foram extraídas de boletins técnicos de associações de classe, consultados aleatoriamente, relatórios de instituições, e muito importante foi a participação na reunião técnica de bibliotecários da Justiça Federal ${ }^{1}$, ocasião em que várias empresas demonstraram seus produtos.

Heeman ${ }^{2}$, em seu trabalho sobre mudança de hábito ocasionada pela automação, alerta que, na sociedade informatizada, a informação passa a fluir livremente, fugindo do controle dos catálogos e acervos, para dentro dos arquivos dos computadores, circulando globalmente de usuário para usuário, sem que possa ser coletada, armazenada e disseminada. Altera-se, assim, o processo de transferência da informação, desde o ciclo produtor/emissor, os suportes, até o destino/receptor.

Esta situação reflete-se também no gerenciamento de acervos bibliográficos e de produtos e serviços informacionais. Enfim, no processo de gestão da informação, que, segundo Davenport ${ }^{3}$, constitui-se de um conjunto estruturado de atividades que incluem o modo como as instituições produzem, obtêm, distribuem e usam a informação e o conhecimento, tendo nos recursos tecnológicos o instrumento facilitador deste processo.

Costa 4 alerta que as bibliotecas contemporâneas convivem com sérios conflitos organizacionais, orçamentos reduzidos e pessoal insuficiente para o desempenho de suas funções atuais e têm enfrentado os desafios oriundos das transformações socioculturais, incorporando o novo papel que lhes cabe na transferência de conhecimentos e informações.

O cenário indica que, se as bibliotecas e centros de documentação quiserem oferecer melhor serviço aos usuários e cumprir sua missão, necessário se torna acompanhar passo a passo o desenvolvimento da sociedade, entender com mais precisão os hábitos e os costumes dos usuários, adaptar as tecnologias às necessidades $\mathrm{e}$ quantidades de informação de que dispõem, assim como utilizar um sistema informatizado que privilegie todas as etapas do ciclo documental, no qual a escolha recaia sobre uma ferramenta que contemple os recursos hoje disponíveis, sem se tornar obsoleto a médio e longo prazos.

Definir esse sistema não é tarefa das mais fáceis, mesmo porque, nos últimos dez anos, houve grande avanço na área de desenvolvimento de sistemas, especialmente em softwares para automação de bibliotecas. Fatores decisivos deste processo foram, sem dúvida, a quebra da reserva de mercados e a introdução da microinformática, em substituição aos sistemas desenvolvidos para ambientes de mainframes.

Os softwares desenvolvidos para aplicações em computadores de grande porte, se, por um lado, possuíam grande capacidade de armazenamento de dados, por outro, não permitiam a alimentação em tempo real e exigiam infra-estrutura computacional com equipes altamente especializadas, ambientes totalmente apropriados, colocando as bibliotecas, os bibliotecários e os usuários totalmente dependentes da tecnologia com pouca agilidade na prestação de serviços. A informação sucumbe-se à tecnologia.

Martinelli ${ }^{5}$ analisa que o processo de informatização das bibliotecas no Brasil passou a viver uma nova fase, caracterizada pela disponibilidade de recursos avançados - máquinas e softwares de nova geração que chegaram ao país nos últimos anos -, apontando como causa, tanto da defasagem como do novo surto de desenvolvimento, as mudanças da política de informática no Brasil, ocorridas a partir de 1993, que proporcionaram o acesso a uma nova geração de equipamentos e softwares.

Ainda, segundo Davenport ${ }^{3}$, a informação não pode ser considerada de maneira isolada nas instituições. Às bibliotecas está reservado o papel de repensar suas atividades e funções, adaptando-se aos novos modelos organizacionais e extraindo das tecnologias disponíveis o substrato para a melhoria na prestação de serviços e na utilização eficaz de informações.

A modernização das bibliotecas está diretamente ligada à automação de rotinas e serviços, com o intuito de implantar uma infra-estrutura de comuni- cação para agilizar e ampliar o acesso à informação pelo usuário, tornando-se necessário haver uma ampla visão da tecnologia da informação e sua aplicação nas organizações.

Epstein, citado por Krzyzanowski6, alerta para o fato de que não existe um sistema ideal e, mesmo que a escolha seja a mais acertada, poderá não atender completamente aos requisitos funcionais (quais atividades serão realizadas) e de performance (quantas atividades serão atendidas e com que rapidez), além de executar o back-up desejado e as operações de proteção, a custo compatível com o orçamento disponível.

Por esse motivo, é importante que a biblioteca determine os seus próprios requisitos obrigatórios e solicite as operações desejáveis somente após certificar-se de que as funções básicas e necessárias estejam plenamente atendidas.

Assim, qualquer iniciativa de informatização de uma biblioteca ou centro de documentação deve, primeiramente, identificar a cultura, missão, objetivos e programas de trabalho da organização; as características essenciais da biblioteca com relação à sua abrangência temática, serviços e produtos oferecidos; os interesses e necessidades de informação dos usuários; a plataforma tecnológica existente na instituição em termos de software e hardware, bem como sua capacidade de atualização e ampliação, além dos recursos humanos disponíveis.

Figueiredo $^{7}$, ao analisar a situação da automação nas bibliotecas universitárias, identificou, entre outros aspectos, que o maior benefício com a implantação do processo de informatização é a rapidez, agilidade e eficiência no atendimento e prestação de serviços, isto é, a otimização das atividades não só com relação aos usuários, como também no que diz respeito ao controle e formação do acervo, levantamentos bibliográficos, catalogação, empréstimos, comutação, reclamação de obras em atraso e processamento técnico.

\section{METODOLOGIA UTILIZADA NA AVALIAÇÃO}

A metodologia utilizada na realização 
deste estudo obedeceu aos seguintes passos:

a) elaboração do diagnóstico das bibliotecas caracterizando acervo, usuários, capacidade institucional, serviços e produtos oferecidos;

b) observância às diretrizes organizacionais;

c) capacidade tecnológica e parque computacional existentes;

d) revisão de literatura na área de automação em bibliotecas;

e) análise de documentos que registram experiências semelhantes;

f) participação em eventos técnicos na área;

g) análise de catálogos, prospectos, folhetos e documentação sobre os softwares disponíveis no mercado;

h) contatos com instituições que acompanham o mercado;

i) contatos com fabricantes de softwares;

j) visitas a usuários para verificar o grau de satisfação, bem como os problemas detectados quando da implantação, acompanhamento e manutenção dos serviços;

k) troca de informações com analistas de sistemas e bibliotecários de instituições públicas e privadas;

I) análise da idoneidade das instituições detentoras dos produtos, procurando evitar a contratação de uma empresa sem história e credibilidade no mercado.

Após cumpridas as etapas anteriormente relacionadas, elaborou-se um instrumento de coleta de dados encaminhado às empresas fornecedoras dos softwares identificados. Este instrumento contemplava, dentre outras, informações técnicas de cada produto, usuários, capacidade institucional da empresa, capacidade tecnológica exigida, bem como os responsáveis técnicos e gerenciais.

Obtidas as respostas, foram agenda- das, para o mês de março de 1998, demonstrações com as empresas e seus respectivos produtos: Potiron Informática, proprietária do OrtoDocs; Fundação Getúlio Vargas, fornecedora do VTLS; Via Ápia Informática, proprietária do Thesaurus; Ex Libris, fornecedora do Aleph; e Modo Novo Consultoria e Informática, proprietária do Informa.

As empresas Dados Informação e Serviços (Dins), proprietária do software Caribe, a Drv Informática, do software Biblio e WA Corbi, do software ArcheS Lib, não demonstraram seus produtos, sendo, porém, avaliados com base no questionário respondido e na documentação encaminhada.

As empresas Contempory, proprietária do software Sysbibli, e a MPS - Informática, do software Sabiá, não enviaram respostas. Como resultados de contatos telefônicos feitos com ambas, a MPS informou que o Sabiá não atendia às especificações da PR. Agradeceram o convite, mas não se propuseram a apresentar o produto.

Assim, foram mantidos contatos com 10 empresas e analisados oito produtos diferentes. Além da demonstração técnica, foram visitados os seguintes usuários: a) Instituto de Planejamento Econômico (Ipea), usuário do OrtoDocs; b) Tribunal Superior Eleitoral (TSE), usuário do Thesaurus; c) Empresa brasileira de Planejamento de Transportes (Geipot), usuário do Thesaurus; d) Senado Federal, usuário do Aleph, em fase de aquisição.

Após a realização das visitas e demonstrações dos produtos, passou-se à análise de todas as informações coletadas, análise que resultou na identificação dos requisitos imprescindíveis e desejáveis que os produtos deveriam contemplar, para atender às necessidades das Bibliotecas da Presidência da República.

\section{REQUISITOS UTILIZADOS NA AVA- LIAÇÃO E SELEÇÃO}

Em que pesem as observações feitas pela equipe, decidiu-se, ao concluir este trabalho, agregar às expectativas iniciais um pouco da experiência final e, assim, sintetizar e ressaltar os requisitos exigidos que devem ser observados quando da escolha de um software, classificando-os como imprescindíveis e desejáveis.

\section{REQUISITOS ESPECÍFICOS}

Requisitos relacionados à tecnologia constituem-se nos itens que identificam a capacidade do sistema de trabalhar com modernos recursos tecnológicos, possibilitando segurança e intercâmbio de dados, tendo como requisitos imprescindíveis:

a) acesso simultâneo de usuários às bases de dados;

b) armazenamento, recuperação e classificação correta dos caracteres da língua portuguesa (Português Brasil): maiúsculas, minúsculas, cedilha e caracteres especiais;

c) arquitetura de rede cliente/servidor;

d) auditoria no sistema;

e) capacidade de atualização dos dados em tempo real;

f) capacidade de elaboração de estatística com geração automática de gráficos;

g) capacidade de suportar acima de 16 (dezesseis) milhões de registros bibliográficos;

h) compatibilidade com os softwares de rede Novell Netware, Microsoft Windows NT ou OS/400;

i) compatibilidade com software de banco de dados relacional e/ou textu$\mathrm{al}$;

j) disponibilidade de help on-line sensível ao conteúdo em língua portuguesa;

k) garantia de manutenção e disponibilização de novas versões;

I) gestão de bases de dados com diferentes tipos de documentos; 
m) interface gráfica;

n) leitura de código de barras;

o) níveis diferenciados de acesso aos documentos;

p) padrão ISO2709;

q) protocolo de comunicação Z39.50;

r) recuperação de base de dados textuais;

s) segurança na forma de registro e de gerenciamento dos dados;

t) senha para as funções que atualizam dados;

u) software cliente: sistema operacional Windows 95 ou superior;

v) tabela de parâmetros para personalizar o funcionamento do sistema;

w) tratamento de textos e imagens;

x) uso de data no formato dia/mês/ano, sendo o ano, com quatro dígitos de uso corrente, na língua portuguesa.

Como requisitos desejáveis, o acesso à base de dados via browser Internet/ Intranet.

\section{Requisitos relacionados ao proces- so de seleção e aquisição caracteri- zam-se por ser o módulo gerenciador do processo de aquisição de materi- ais bibliográficos, por doação, permu- ta e compra, tendo como itens impres- cindíveis:}

a) controle de todo o processo de aquisição;

b) controle de listas de sugestão, seleção, aquisição, reclamações e recebimento;

c) controle de assinatura de periódicos: início, vencimento, renovação e datas previstas para recebimento dos fascículos; controle de recebimento de fascículos de periódicos e seriados;

d) identificação de dados do processo de aquisição (número de processo, número de empenho, preço, número da nota fiscal ou fatura, outros.); e) identificação da modalidade de aquisição (doação, compra, permuta, depósito legal).

\section{Como requisitos desejáveis:}

a) controle de datas de recebimento do material adquirido;

b) controle contábil e financeiro dos recursos orçamentários para aquisição de material bibliográfico;

c) controle de fornecedores por compra, doação e permuta; emissão de cartas de cobrança, reclamações e agradecimento de doações;

d) elaboração de lista de duplicatas;

e) elaboração de lista de desideratas;

f) estatística mensal e acumulada de documentos recebidos;

g) cadastro de entidades com as quais mantém intercâmbio de publicações;

h) controle da situação (status) do documento bibliográfico (encomendado, aguardando autorização, aguardando nota fiscal, encaminhado para pagamento e outros);

i) identificação do usuário que sugeriu o título para aquisição.

Requisitos relacionados ao processamento técnico dos documentos, um módulo gerenciador do registro das informações bibliográficas, segundo padrões internacionais, privilegiando os seguintes requisitos imprescindíveis:

a) atualização em tempo real do banco de dados, nos registros de autoridade e demais índices, após o envio de novo registro ao servidor;

b) campos e códigos de catalogação de qualquer tipo de documento, inclusive artigos de periódicos, de acordo com o AACR2;

c) capacidade de armazenar informação legislativa;

d) código de barras para cada documento; e) construção automática de lista de autoridades a partir dos registros incluídos;

f) construção de remissivas para autores/assuntos;

g) consulta ao tesauro, lista de autoridades e lista de editoras, durante 0 cadastramento de um registro;

h) correção de todos os registros associados a um autor ou assunto mediante alteração na lista de autoridade ou tesauro;

i) exportação de dados para alimentação de bases de dados de catalogação cooperativa;

j) formato MARC dos registros bibliográficos;

k) geração de etiquetas para bolso e lombada dos documentos;

I) importação de dados de centros de catalogação cooperativa on-line e cdrom;

m) inclusão de referências, de alterações, revogações e republicações para atos normativos/legislação;

n) incorporação de textos digitados sistema de gerenciamento de texto, imagem e som para inclusão de inteiro teor de atos normativos e resumos de periódicos;

o) possibilidade de duplicação de um registro para inclusão de novas edições;

p) possibilidade de validação dos registros e campos;

q) processamento de materiais especiais, obras raras e outros;

r) sistema de gerenciamento para construção de tesauro.

Requisitos relacionados ao processo de empréstimo de documentos, módulo que gerencia o uso e circulação dos documentos da Biblioteca, cumprindo os seguintes procedimentos imprescindíveis: 
a) aplicação de multas e suspensões; etc;

b) bloqueio automático de empréstimo sempre que o usuário estiver em atraso ou com dados cadastrais desatualizados;

c) cadastro de usuários, com inclusão, exclusão e alteração de nomes e endereços, com categorização de usuários;

d) categorização de empréstimo: empréstimo domiciliar, especial e empréstimo entre bibliotecas:

e) categorizarão de usuários e de materiais para fins de definição automática de prazos e condições de empréstimos e uso;

f) cobrança personalizada; com prazos diferenciados por tipos de materiais e usuários;

g) código de barras para cada leitor;

h) controle de devoluções, renovações, atrasos;

i) controle de usuários pessoais e institucionais;

j) controle dos leitores em atraso;

k) definição de parâmetro para a reserva de livros, com senhas de segurança;

l) emissão de cartas cobrança automática para usuários em atraso;

m) emissão de relação de obras que estão em poder dos leitores;

n) emissão de relatórios referentes ao processo de empréstimo: assuntos mais consultados no período, usuário que maior número de empréstimo realizou;

o) incidência de atrasos em relação aos períodos anteriores, unidade organizacional que mais consultou a biblioteca;

p) emissão de senhas para os empréstimos;

q) possibilidade de pesquisar a situação em que se encontra o exemplar: disponível, emprestado, encadernado, r) realização de empréstimo, devolução, renovação e reserva, on-line;

s) registro de solicitação de fotocópias;

t) relatórios do cadastro de usuários, por ordem alfabética, formação, unidade de trabalho;

u) reserva de documentos, com prazos diferenciados por tipos de materiais e usuários;

v) rotina completa de empréstimo para qualquer tipo de documento;

w) senha para os empréstimos.

Requisitos relacionados ao processo de recuperação de informações constituem-se em recursos especiais de pesquisa para localizar documentos em múltiplas bases de dados, com filtragem de resultados e combinações de conjuntos, agregando as características imprescindíveis:

a) capacidade de ordenar e classificar os documentos pesquisados;

b) capacidade de permitir que os resultados de pesquisas sejam gravados em disquetes ou arquivos;

c) consulta à Internet; elaboração de estatísticas;

d) estratégia de pesquisa on-line nas bases de dados por qualquer palavra, campo ou subcampo;

e) indicação do status do documento pesquisado, se emprestado, em encadernação ou disponível; possibilidade de envio do resultado da pesquisa por e-mail, ao usuário;

f) possibilidade de salvar estratégias de buscas para utilização posterior;

g) recuperação por truncamento à esquerda, à direita e ao meio, operadores booleanos, proximidade e distância entre termos:

h) visualização do resultado da pesqui- sa em forma de referência bibliográfica breve e completa, de acordo com a ABNT.

Requisitos relacionados ao processo de divulgação da informação, módulo gerenciador das atividades de divulgação, contribuindo para o processo de disseminação de informações, com os seguintes atributos imprescindíveis:

a) emissão de listas de publicações por assuntos e autores;

b) geração de catálogo coletivo;

c) diferentes formatos de visualização de registros on-line e em relatórios tipo ABNT e AACR2;

d) elaboração e impressão de bibliografias em formato ABNT;

e) definição de instrumentos de alerta e disseminação seletiva de informações, conforme perfil dos usuários;

f) pesquisa por conceitos com utilização de tesauro ativo.

\section{Requisitos relacionados ao proces-} so gerencial, módulo que permite o acompanhamento e avaliação das atividades da biblioteca do ponto de vista gerencial, tendo como requisitos imprescindíveis:

a) gerenciamento integrado dos dados e funções da biblioteca;

b) gerenciamento dos tipos de material bibliográfico e informacionais utilizados em bibliotecas;

c) contabiliza estatísticas de circulação, processamento técnico, seleção, aquisição e intercâmbio, atualização de tesauro e listas de autoridades, por período;

d) emite relatórios de circulação por assuntos mais consultados;

e) emite relatórios de circulação por tipo de documentos, por período e acumulado;

f) emite relatórios de empréstimos, por períodos; 
g) emite relatórios de entrada e recebimento de documentos, por período;

h) inventário com utilização do coletor de dados inteligente;

i) listas de usuários, por categorias.

\section{REQUISITOS GERAIS}

\section{Treinamento}

O processo de automação de bibliotecas possui certa complexidade que pode ser minimizada com um treinamento adequado. Não se trata, simplesmente, da instalação de um produto, e sim da implantação de uma nova filosofia de trabalho em que todas as atividades do ciclo documental estão refletidas. É um item importante no processo de escolha, pois habilitará o usuário na utilização do produto, devendo abranger os seguintes níveis:

a) nível técnico: possibilitar aos analistas de sistemas a perfeita compreensão da filosofia de funcionamento do produto, capacitando-os a efetuar a parametrização e disponibilização do sistema para o usuário final;

b) nível gerencial: possibilitar à gerência da Biblioteca a perfeita compreensão dos procedimentos gerenciais oferecidos pelo sistema;

c) nível operacional: possibilitar aos bibliotecários a perfeita compreensão dos procedimentos e rotinas específicos de cada módulo do sistema, inclusive capacitando-os a realizar o treinamento aos usuários, nos módulos pertinentes.

O contratante deve solicitar ao responsável pelo treinamento o provimento do material didático e manuais necessários, devendo estes serem compatíveis com a versão do software licenciado.

\section{Instalação, testes e garantia}

Tal qual o treinamento, esta etapa é muito importante, na medida em que garantirá agilidade e segurança na implementação das rotinas, bem como o assessoramento para a transmissão de conhecimentos indispensáveis ao perfeito uso do produto não transmitidos nos treinamentos. Para tanto, deve-se exigir do fabricante ou vendedor que o produto seja instalado e testado, com o acompanhamento dos técnicos da instituição. Para evitar maiores sobressaltos com a instalação do produto, poder-se-á exigir que o mesmo seja totalmente substituído caso venha ocorrer o mesmo tipo de erro, por três vezes, em um período de 30 dias.

\section{Suporte técnico e manutenção}

É imprescindível firmar com o fornecedor um contrato de suporte técnico e manutenção preventiva e corretiva incluindo os seguintes serviços: correção de erros do software licenciado; fornecimento e implantação de versões atualizadas, com os manuais e literatura técnica pertinentes em português (Brasil); apoio técnico no período de implantação de novas versões, tendo em vista a eventual conversão de aplicações decorrentes de novos dispositivos ou componentes introduzidos; treinamento e reciclagem de servidores, visando à perfeita compreensão das novas versões. A manutenção deverá ser feita procurando facilitar e reduzir ao máximo o tempo entre a identificação e correção dos problemas apresentados.

\section{Documentação}

Mesmo com as facilidades tecnológicas disponíveis, é recomendável que a documentação do produto seja apresentada em português (Brasil ), na forma impressa, e que o fornecedor entregue um conjunto completo de manuais técnicos e do usuário.

\section{Condições institucionais}

O software a ser adquirido deve, além de atender às necessidades de informação, ser compatível com o desenho e cultura organizacional, com o parque computacional instalado, tamanho do acervo e o perfil dos usuários, respeitadas suas características quantitativas e qualitativas. Por vezes, os sof- twares possuem excelentes qualidades de portabilidade de dados e avanços tecnológicos, características que não serão utilizadas em sua totalidade pela biblioteca, e sua aquisição pode tornar-se mais onerosa, ao passo que a opção poderá ser pela escolha de um software com menor capacidade, mas que atenderá melhor às necessidades atuais e aquelas que poderão surgir com o passar do tempo.

Importante também é verificar a idoneidade da empresa fornecedora do produto. Muitas, com a mesma facilidade com que surgiram, sucumbiram ao mercado, deixando os usuários e clientes totalmente desprotegidos. Em alguns casos, as instituições tiveram de realizar nova aquisição, arcando com os custos de novas migrações de dados, troca de equipamentos e outros. Convém ainda verificar a carteira de clientes, a satisfação dos mesmos com o produto, os tipos de problemas que aconteceram na implantação do sistema e como estes foram resolvidos, a saúde financeira da empresa, suas parcerias, ou seja, outras empresas com as quais mantenha trabalhos conjuntos. Uma forma de proteger a instituição é a assinatura de um termo de compromisso onde a empresa produtora do software compromete-se a fornecer os programas fonte da última versão do sistema, nos casos de falência, concordata, simples extinção ou mudança de ramo de atuação.

\section{A QUESTÃO DA CONVERSÃO RE- TROSPECTIVA}

As bibliotecas, ao iniciar o processo de automação, possuem, na maioria das vezes, um acervo acumulado contendo o registro bibliográfico de diversos tipos de documentos, acervo este organizado manualmente com a elaboração de fichas catalográficas dispostas em ordem alfabética por autor, título e assunto, ou mesmo em sistemas 
informatizados. Qualquer que seja a opção pelo software, a biblioteca precisará incluir estes registros no novo sistema. A esta ação denomina-se Conversão Retrospectiva (CR), que significa converter os dados existentes. Algumas metodologias ou formas de realizar este trabalho podem ser utilizadas. Para as fichas, a opção mais tradicional é a digitação de todos os registros no novo sistema. Esta atividade pode ser mais demorada, mas, por vezes, é recomendável, pela garantia da qualidade do resultado final.

Outra solução é a digitalização destas fichas. $\mathrm{O}$ arquivo resultante deste processo será convertido eletronicamente e incorporado à base de dados. Podese também, buscar em outras bases, pela consulta direta ou digitalização das fichas, o registro catalográfico e incorporá-lo à nova. Para o acervo que está em meio magnético, um programa de conversão de dados pode ser utilizado. A decisão de qual caminho será tomado para fazer a CR é muito importante. Em primeiro lugar, no momento da escolha do software, deve ser observado se o produto tem condições de fazer a conversão no meio magnético disponível na biblioteca. Em segundo lugar, a relação custo/benefício indicará a melhor decisão, considerando os recursos disponíveis, o tempo, a expectativa e o planejamento de que a biblioteca dispõe para estar com a base completa (backlog zero).

\section{COMPATIBILIDADE COM FORMATOS PADRONIZADOS DE REGISTROS BIBLIOGRÁFICOS}

\section{A ISO 2709}

A norma ISO 2709 - Documentation Format for Bibliographic Interchange on Magnetic Tape foi desenvolvida pelo Comitê Técnico ISO/TC 46, Informação e Documentação, Subcomitê SC 4 - Aplicativos de computador na informação e documentação, da
International Organization for Standardization (ISO). Esta norma especifica os requisitos para o formato de intercâmbio de registros bibliográficos que descrevem todas as formas de documentos sujeitos à descrição bibliográfica. Não define a extensão do conteúdo de documentos individuais e nem designa significado algum para os parágrafos, indicadores ou identificadores, sendo essas especificações as funções dos formatos de implementação.

Os dados, em meio magnético, estão estruturados de forma a possibilitar o intercâmbio de registros bibliográficos. Porém, esta característica não elimina a incompatibilidade entre os registros que utilizam diferentes formatos de entrada e, principalmente, diferentes regras de entrada de dados. A ISO se preocupa em apresentar uma estrutura generalizada, ou seja, um arcabouço projetado especialmente para a comunicação entre sistemas de processamento de dados, e não para uso como formato de processamento dentro dos sistemas. Da forma como foi estruturada, é item indispensável que deve ser contemplado pelos produtores de softwares para automação de bibliotecas, pois possibilita a padronização entre registros no que se refere à estrutura para intercâmbio de informações que, do ponto de vista técnico, é a base filosófica que norteia, direciona e fundamenta as ações de uma biblioteca. Este preceito legitima o uso desta norma nos processos de automação.

\section{O protocolo Z39.50}

Protocolo 8 originalmente proposto em 1984 para ser utilizado com informações bibliográficas pela National Information Standard Organization (Niso). Foram disponibilizadas as versões 1988, 1992, 1994 e, finalmente, aprovado com a versão 1995. É o protocolo próprio para recuperação de informação bibliográfica de computador para computador, possibilitando ao usuário de um sistema pesquisar e recuperar informações de outro sistema, ambos implementados neste padrão. Especifica formatos e procedimentos administrando a troca de mensagens entre um cliente e um servidor, habilitando o cliente a solicitar que o servidor consulte um banco de dados, identifique registros e recupere um ou todos os dados identificados. Destina-se à comunicação entre aplicações para recuperação de informações, e não promove a interação entre o cliente e o usuário.

O cliente é o computador pessoal ou a estação de trabalho do usuário que executa parte ou todo o processamento do aplicativo. O servidoré o computador central que mantém os bancos de dados e atende a solicitações dos clientes. O padrão Z39.50 é um padrão de "midleware" cliente-servidor. Isto quer dizer que fica entre a comunicação do cliente com o servidor. Com o uso deste padrão, permite-se que determinado servidor possa usar os serviços de diversos servidores ou fornecedores diferentes, e um determinado servidor possa prestar serviços para diversos clientes ou fornecedores. Para exemplificar e melhor esclarecer, se este protocolo não existisse, a biblioteca que quisesse recuperar registros bibliográficos de vários bancos de dados deveria dispor de tantos clientes quantos fossem os catálogos ou bancos de dados que se quisesse consultar.

Certamente é mais um instrumento tecnológico disponível para facilitar o processo de intercâmbio bibliográfico. As informações aqui apresentadas sobre o Protocolo Z39.50 são aquelas necessárias e suficientes à compreensão do bibliotecário. Tal qual a ISO 2709 , este protocolo deve ser utilizado com maior habilidade pelos analistas de sistemas do que pelo bibliotecário.

\section{O formato MARC}

Os estudos ${ }^{9}$ realizados pela Biblioteca do Congresso dos Estados Unidos da América (LC) sobre a possibilidade de usar os recursos computacionais para automatizar parte de seus serviços internos deram início na década de 50. Na medida em que apresentavam resultados positivos, a direção da Biblioteca decidiu convocar um grupo de trabalho integrado por bibliotecários e analistas de sistemas para encontrar uma forma de converter os dados 
das fichas catalográficas, gerando o repertório bibliográfico. O sucesso das ações da LC extrapolou sua abrangência institucional, e o desenvolvimento de formatos bibliográficos nacionais gerou preocupação em vários países que começaram a discutir sobre a necessidade de dispor de um formato que permitisse a troca de informações entre instituições, dispensando a elaboração de programas de conversão de registros a cada vez que ocorresse intercâmbio entre essas instituições.

Começou desta forma, no início de 1966, um projeto-piloto para a LC estudar a possibilidade de fornecer às bibliotecas dados de catalogação legíveis por máquina. Este projeto-piloto denominou-se Marc - Machine-Readable for Cataloging - e teve como objetivo desenvolver procedimentos e programas de conversão, manutenção de arquivos e distribuição de dados compatíveis com o formato.

A LC, em 1966, concluiu o trabalho de formulação de procedimentos, rotinas e programas de computador denominado Marc I, o formato do projeto-piloto que incluía somente a descrição de livros. O sucesso deste formato e as negociações e acordos realizados durante sua implantação levaram as bibliotecas a pensar em um formato padrão de comunicações, adequado não só ao intercâmbio de dados bibliográficos na LC, mas também às demais, surgindo o Marc II com o propósito de desenhar a representação física de documento, em um meio legível por computadores, capaz de conter informação bibliográfica de todo tipo de material $^{10}$. Realizou, ainda, um estudo de viabilidade para a elaboração de metodologias e formas de realização de Conversão Retrospectiva, projeto denominado de Recon (Retrospective Conversion), cujo resultado foi publicado em 1969.

Poucos sistemas de automação de bibliotecas utilizam o Marc puro, integral, embora muitos registros e sistemas sejam compatíveis com o mesmo. Os modernos softwares de automação de bibliotecas estão facilitando esta tarefa, deixando a cargo do sistema a transformação dos dados de catalogação para o formato Marc, obedecidas, evidentemente, as característi- cas mínimas de descrição bibliográfica. Diferentemente da ISO 2709 e do protocolo Z39.50, o formato Marc é ferramenta de domínio exclusivo do bibliotecário que o utiliza na atividade de descrição bibliográfica.

\section{DESCRIÇÃO DOS SOFTWARESAVA- LIADOS}

Os dados obtidos permitiram à equipe elaborar um cenário das empresas e produtos oferecidos, a saber:

\section{Potiron Informática Sociedade Civil Ltda., responsável pelo software OrtoDocs}

A Potiron Informática, com sede na cidade de São Paulo e laboratório tecnológico em Campinas-SP, é uma empresa com 13 anos de experiência no mercado. Nos últimos cinco anos, tem orientado seus produtos para o segmento de automação de bibliotecas e centros de documentação, especializando-se, portanto, nesta área quando desenvolveu o OrtoDocs. Possui uma equipe de cerca de 25 bibliotecários, garantindo equilíbrio entre a parte tecnológica e de conteúdo.

Como metodologia de trabalho, elabora, inicialmente, o projeto de informatização da Biblioteca. Com a experiência adquirida na implantação do OrtoDocs em outras bibliotecas, a Potiron faz as seguintes recomendações: a existência de um servidor dedicado para residir o OrtoDocs; definição clara de cada etapa do projeto; a conversão retrospectiva de dados como atividade à parte e realizada na própria Potiron, o que garantirá o funcionamento normal da biblioteca durante o período de implantação; a gravação em cdrom das bases de dados da biblioteca.

Afirma que a postura, enquanto empresa, foi de sempre estar acompanhando a evolução dos projetos importantes, de clientes ou não, no Brasil e fora do país, mantendo-se atualizada com o que está acontecendo e para onde os caminhos apontam, sempre atenta à realidade brasileira e dos clientes. Oferece, assim, os serviços de acompanhamento do projeto de informatização de bibliotecas, aplicando sua experiência na implantação, acompanhamento e adequação do OrtoDocs a cada realidade institucional.

A conversão retrospectiva, conforme entendida pela Potiron, deve ser "confinada na representação das obras do acervo que não estão em meio magnético, ou seja, é o esforço empregado para eliminar uma lacuna construída ao longo do tempo e que tem como causa a ausência dos recursos necessários para realizar o processo adequado de informatização. Depois de atingido o ponto de equilíbrio entre objetos e representações no acervo que pode ser o equilíbrio total o qual denominamos de backlog zero, a manutenção desta situação não tem mais o caráter de retrospectivo, mas o de desenvolvimento do fluxo de trabalho cotidiano".

O método escolhido pela Potiron, para a $\mathrm{CR}$, é o de digitalização das fichas catalográficas, por ser um processo que causa menores alterações no fluxo de trabalho normal das bibliotecas. Estas fichas são levadas para a sede da Empresa, e as imagens, digitalizadas, após o que se inicia a pesquisa em outras bases de dados. Em caso de coincidência na procura, o registro é copiado para a base receptora e são promovidas as alterações necessárias para a completa inclusão na base de dados da instituição.

Para a conversão de registros em meio magnético, a Potiron gera um dialeto que é a exata representação dos campos especificados na base do cliente. A migração dos dados para o OrtoDocs segue a descritiva encaminhada, e o conteúdo dos dados não é alterado. Da mesma forma que o registro existia em outro ambiente, é capturado pelo OrtoDocs. Fisicamente é alterado para obedecer ao padrão Marc podendo ser exportado conforme a ISO 39.2. Há casos em que os registros são exportados e os dados revisados segundo as descritivas do padrão Marc. O registro mantém o mesmo conteúdo do original, porém distribuído pelos parágrafos seguindo os conceitos do MARC, inclusive com a geração automática do parágrafo 008 , que é um campo de referência que fornece dados necessários ao processamento do registro, não contendo indicadores ou identificadores. O resultado final é um registro Marc. 
Outra forma de conversão de dados utilizada pela Potiron é quando os registros originais servem de fonte para a CR, utilizando outras bases como referência. Dessa forma, os registros magnéticos substituem a digitalização das fichas catalográficas que segue processo idêntico ao descrito anteriormente.

A depuração de bases é feita pelo Serviço de Normalização com a aplicação dos conceitos do Código de Catalogação Anglo-americano - AACR2, verificação das regras básicas e aplicação das alterações da versão atualizada do MARC quanto a parágrafos obsoletos, mudanças de descritivas e outros.

Sua carteira é composta por clientes de pequeno, médio e grande porte localizados em grandes centros ou cidades em vários estados. Em Brasília, o Instituto de Pesquisa Econômica Aplicada (Ipea). No Rio de Janeiro, a Biblioteca Nacional, o Instituto Brasileiro de Geografia e Estatística (IBGE) e o Serviço de Documentação da Marinha. Na Bahia, a Universidade Federal da Bahia, a Universidade Estadual de Feira de Santana. Em Minas Gerais, a Prefeitura de Diadema. No Rio Grande do Sul, Universidade Regional Integrada de Erechim.

O OrtoDocs é um sistema para informatização de bibliotecas individuais ou interligadas em redes, com todas as suas atividades integradas: catalogação segundo o padrão AACR2 para todos os tipos de materiais; controle patrimonial, de circulação e de periódicos, pesquisa bibliográfica, aquisição de materiais, importação e exportação de dados e geração de relatórios, utilizando o software ReportSmith, tornando possível as saídas de dados impressas de acordo com as peculiaridades e necessidades de cada biblioteca.

Adota o formato Usmarc, incorporando sempre as suas mais recentes revisões e atualizações, facilitando o intercâmbio de registros bibliográficos, com base no padrão Z39.50. É um software totalmente desenvolvido no Brasil. Foi concebido desde o início para o ambiente Microsoft Windows, em arquitetura Cliente - Servidor e compatibilidade com qualquer banco de dados no padrão Idapi ou ODBC. Atento a diferentes perfis de clientes e suas aplicações, é comercializado nas seguintes modalidades: OrtoDocs Pessoal-somente o módulo de pesquisa; OrtoDocs Profissional - conjunto de ferramentas para o profissional bibliotecário; Corporativo OrtoDocs WebPack - pacote com extensões para alcance fora da instituição, via Internet.

O OrtoDocs Pessoal é para uso específico do usuário final (pesquisadores, alunos, departamentos ou residências). Contempla o módulo de pesquisa pública e deve ser instalado nas estações da rede interna da instituição como quiosques de atendimento aos usuários, estações externas à biblioteca. Permite aos usuários o acesso ao acervo com todas as facilidades e atributos do módulo profissional de atendimento. Não possui contrato de manutenção e é atualizado pela aquisição de novas versões.

O OrtoDocs Profissional é o produto voltado para o ambiente profissional da biblioteca. Contempla as funções de processamento técnico, atendimento ao público, circulação, aquisição e intercâmbio. Vem configurado na sua versão completa e contempla o treinamento de uso do processamento técnico. O módulo completo prevê as funções de importação de dados, exportação de registros, catalogação, pesquisa pública On-line Public Access Catalog (OPAC), circulação, controle de periódicos, aquisição e intercâmbio. O contrato de manutenção do OrtoDocs Profissional assegura o perfeito funcionamento do produto e garante, aos clientes, o recebimento das versões atualizadas. É também oferecido o serviço de suporte ao cliente para o esclarecimento de questões quanto ao produto ou ao projeto institucional. Os contatos são feitos via Internet, fax ou telefone, seguidos de um rigoroso acompanhamento interno dos encaminhamentos sugeridos, bem como seus resultados.

O OrtoDocs Web Pack é um módulo cuja função é colocar, à disposição de uma rede externa, os dados do acervo para pesquisa pública. Os usuários finais que estiverem acessando via uma estação com OrtoDocs, profissional ou pessoal, estarão utilizando os mesmos recursos como se estivessem na rede interna. Os usuários que não dispuserem do OrtoDocs, mas utilizarem um software que siga o padrão Z39.50 versão 2 - somente consulta, estarão utilizando os recursos nativos do seu aplicativo particular. Os usuários que não se enquadrarem em nenhum dos casos anteriores terão acesso pelos browsers convencionais. O contrato de manutenção assegura o funcionamento e as novas versões.

Na Biblioteca do Ipea, em Brasília, constatou-se grande satisfação pelo atendimento recebido da Potiron, a presteza na assistência técnica, na solução dos problemas identificados e a flexibilidade apresentada pelo OrtoDocs de adaptar-se às peculiaridades da instituição. Um analista de sistemas foi designado para acompanhar, junto com o bibliotecário, o processo desde a fase de escolha do produto até sua implantação. A decisão naquela instituição foi realizar a migração dos dados da antiga base no formato Cepal (Comissão Econômica para a América Latina) - software GIBI - para o formato Marc, sendo que todas as dificuldades apresentadas foram resolvidas. Foram atendidas inicialmente pelo OrtoDocs as Bibliotecas do Rio de Janeiro e Brasília e, posteriormente, as do Ministério do Planejamento e Orçamento e a da Secretaria de Planejamento, em razão do trabalho em rede entre elas. Atualmente, o software tem o perfil do Ipea, em função das adaptações feitas às realidades institucionais, caracterizando-se flexível e de fácil adaptação. O tempo gasto do início do processo de escolha até a assinatura do contrato foi de aproximadamente 12 meses. Da assinatura até a instalação e implantação incluindo a migração do formato Cepal para o formato Marc, foram mais 12 meses. Os módulos processamento técnico, pesquisa e circulação já estão implantados e em funcionamento.

Nunes, Silva e Ribeiro ${ }^{11}$, em trabalho apresentado no X Seminário Nacional de Bibliotecas Universitárias, em Fortaleza, no período de 25 a 30 de outubro de 1998, discorrem sobre o processo de informatização da Biblioteca da Universidade Estadual de Feira de Santana, onde foi utilizado o OrtoDocs. A capacidade de adequação desse sof- 
tware com a situação existente naquela biblioteca, onde outras experiências haviam sido iniciadas, a flexibilidade nas negociações, a parceria com a Potiron e as respostas às questões inicialmente formuladas que fundamentaram a necessidade de investir na automação foram itens de sucesso e a certeza de que a opção pelo OrtoDocs foi correta.

\section{Fundação Getúlio Vargas (FGV), responsável pelo software Virgínia Tech Library System - VTLS 500}

É inegável e irrefutável a idoneidade da FGV como instituição perante a sociedade civil e acadêmica. Sua sede fica na cidade do Rio de Janeiro e mantém, em São Paulo, a Escola de Administração de Empresas (Eaesp), com autonomias institucionais.

$\mathrm{Na}$ área de descrição bibliográfica cooperativa possui cerca de 20 anos de experiência, quando, utilizando a tecnologia de computador de grande porte desenvolveu e implantou um sistema que deu sustentação à Rede Bibliodata constituída por mais de 100 bibliotecas nacionais que integram o Sistema Bibliodata/Calco, uma das maiores bases de dados bibliográficos do país. Como saída para a crise vivenciada no início da década de 90 , a Fundação decidiu investir e concentrar esforços na área de softwares para bibliotecas. Para tanto, analisou mais ou menos cinco softwares procedentes dos Estados Unidos. A partir de 1993, decidiu assumir a representação do Vtls - Virgínia Tech Library System -, um aplicativo desenvolvido pela Universidade da Virgínia, utilizado em diversas bibliotecas americanas, há cerca de 20 anos. Uma das razões desta escolha foi a facilidade de o Vtls utilizar o Catálogo Coletivo resultante da Rede Bibliodata Calco.

Mantém uma equipe de bibliotecários e analistas que dão suporte ao Vtls, todos treinados nos Estados Unidos da América, garantindo a manutenção direta da Universidade de Virgínia, caso os problemas não sejam resolvidos pela FGV, em tempo hábil. É a instituição responsável pela tradução do software para o português e acompanha todas as novas versões do produto.
Ao adquirir o Vtls, a FGV elabora, junto com a instituição, o projeto de automação. A conversão ou migração de dados é feita tendo como fonte somente os dados em meio magnético. Caracteriza-se como trabalho intelectual merecendo um projeto específico. A fundamentação é o formato Marc. Para o acervo que não se encontra em meio magnético, recomenda a inclusão direta dos dados, e não sua digitalização.

Com sua experiência, orientou que as questões mais importantes a serem verificadas quando da escolha de um software dizem respeito ao uso do formato Marc, do padrão ISO 2709 e do suporte do Z39.50, que é o protocolo cliente/servidor desenvolvido para bibliotecas; que nenhum sistema é totalmente completo e que o usuário só o conhecerá após dois anos de uso. Sua carteira inclui 250 clientes fora do Brasil, além das bibliotecas da Universidade Federal de Minas Gerais, as da FGV, no Rio de Janeiro e em São Paulo, a Universidade Estadual de Santa Catarina, a Universidade de Campinas (Unicamp), a Pontifícia Universidade Católica de Campinas (Puccamp) e a Biblioteca do Estado Maior das Forças Armadas (EMFA), em Brasília.

O Vtls 500 é um software exclusivo para automação de bibliotecas, desenvolvido para um ambiente universitário, objetivando a melhoria na prestação dos serviços ao usuário. Possui certificação ISO - 9002, adotando o formato Usmarc, a ISO 2709 e o protocolo Z39.50. Realiza a conversão de dados, desde que no formato Usmarc ou Unimarc.

A atualização da base é feita de três maneiras, de acordo com a escolha da biblioteca, quais sejam: a) off-line - captura os dados do CD e transforma em registro Marc; b) on-line - 0 registro fica armazenado em um banco de dados auxiliar buffer, aguardando ser executado um serviço, após o que são enviados para o catálogo (neste período, podem ser consultados pelo catalogador, mas não aparecem na pesquisa e nem estão ainda indexados); c) real-time - os registros, após entrarem no buffer, vão automaticamente para o catálogo.

O Vtls 500 não possui base para registro de informação legislativa, não emite bibliografias e não visualiza os registros em relatórios tipo $A B N T$ e AACR2. Ainda não está disponível o módulo de disseminação seletiva de informações. Para cada nova edição, é criado novo registro bibliográfico, ao passo que as reimpressões podem ser incluídas em um só registro, seguindo as normas técnicas do formato Marc e do AACR2, reconhecidos internacionalmente. É um sistema integrado e modular, compreendendo os seguintes subsistemas: consulta, catalogação, controle de autoridade, controle de periódicos, controle de circulação, controle de sala de reservas, aquisição e administração contábil, interface Z39.50 e comutação bibliográfica.

\section{VIA ÁPIA INFORMÁTICA, RESPONSÁVEL PELO SISTEMA THESAURUS DE CONTROLE DE BIBLIOTECAS}

A Via Ápia Informática é uma empresa totalmente voltada para soluções na área de automação de bibliotecas e centros de documentação. Tem sua sede em Brasília, com aproximadamente cinco anos no mercado. Desenvolveu o Sistema Genesys de Informações, que trata conteúdo, som, imagem, vídeos e implementa biblioteca virtual; o Sistema Thesaurus de Controle de Bibliotecas, que trata a catalogação, a referência, a pesquisa e a circulação.

Oferece serviços técnicos de biblioteconomia, a saber, o processamento técnico, digitação, etiquetamento e higienização; planejamento e organização de bibliotecas. Em relação à Internet a criação de home page, o domí- 
nio na ferramenta, IP discado e rede cooperativa. Não possui representante comercial. A própria empresa é quem se encarrega de toda a parte de comercialização, distribuição, instalação e manutenção do software.

Trabalha em parceria com várias empresas, entre elas, a Link Informática e Serviços, que desenvolveu um sistema de patrimônio utilizando código de barras aplicável em bibliotecas e centros de documentação, a Padrão iX, detentora dos direitos autorais do BRS Search, banco de dados textual utilizado na parte de recuperação de informações, a IDS, que desenvolveu o software Datalegis, específico para o armazenamento, tratamento e difusão de informações legislativas, e a Companhia de Processamento de Dados do Estado do Rio Grande do Sul (Procergs), que optou pela parceria com a Via Ápia, após realizar trabalho comparativo com outros softwares de bibliotecas e constatar que o Thesaurus atendia a todos os pré-requisitos por ela exigidos.

A empresa conta com um quadro de profissionais qualificados para prestação de serviços que vão desde a higienização até o processamento técnico do acervo e uma equipe exclusiva de analistas para suporte ao sistema. A CR é feita utilizando a metodologia da migração de dados em meio magnético. Para as fichas catalográficas, recomenda a inclusão direta no sistema, evitando a digitalização das mesmas.

A manutenção dá direito à atualização de versões. Toda solicitação de alteração no sistema para atender a uma necessidade de determinado usuário é encaminhada e discutida com os demais usuários, de forma a que todos se beneficiem das melhorias propostas. Tem como usuários, em Brasília, as Bibliotecas do Ministério da Justiça, do Tribunal de Contas da União, Tribunal Superior do Trabalho, Tribunal Superior Eleitoral, Empresa Brasileira de Planejamento de Transportes (Geipot), Associação de Ensino Unificado do Distrito Federal (AEUDF), Fundação Nacional de Saúde, Colégio La Salle, a Universidade Católica de Brasília; em Goiás, a Telegoiás; em São Paulo, a Fundação Jorge Duprat Figueiredo de Segurança e Medicina do Trabalho (Fundacentro).

O Thesaurus é um software específico para a automação de bibliotecas e centros de documentação. Inicialmente foi desenvolvido, sob demanda, para atender às necessidades do Departamento Nacional de Águas e Esgotos (DNAEE) e da Associação de Ensino Unificado do Distrito Federal (AEUDF), sendo aperfeiçoado no decorrer dos tempos de acordo com as avaliações feitas por bibliotecários.

Com relação ao questionário enviado pela $\mathrm{PR}$, informou não realizar o controle contábil e financeiro de aquisições e não permitir a inclusão de novas edições em um mesmo registro bibliográfico, sendo que reimpressões podem ser incluídas em um só registro, de acordo com as normas técnicas. Desenvolvido em ambiente gráfico, dentro da arquitetura cliente/servidor, nas quais atinge sua melhor performance permitindo a utilização simultânea, guarda compatibilidade com as plataformas Windows NT, Novell, OS/2, Unix via TCP/IP e mainframe via emulador de terminal, funcionando perfeitamente em clientes Windows 95, 3.1, 3.11 e OS/2. Pode utilizar como backend bancos de dados tais como o Oracle, SQL Server, SQL Base, Sysbase, Ingress e outros existentes no mercado.

Abrange todo o ciclo operacional das bibliotecas, indo desde o cadastramento inicial dos usuários autorizados até a realização do balanço. Oferece vários tipos de relatórios de controle que podem ser impressos ou visualizados em tela. Incorpora a plena utilização de códigos de barras que, aplicados aos livros, prateleiras e carteirinhas de leitores, automatizam os procedimentos, facilitando sensivelmente a atuação do elemento humano. Possui ferramenta própria para importação, exportação e conversão automática de dados no formato Usmarc, e os registros catalográficos podem ser feitos de maneira livre, atentando para as normas de catalogação AACR2. No momento da importação de registros catalográficos, promove o controle automático do vocabulário, utilizando o tesauro já carregado na base do sistema, gerando lista de descritores sem redundâncias.

Contempla os módulos de referência, aquisição, circulação, processamento técnico e estatísticas. Trabalha com tabelas auxiliares de atos normativos, tipos de andamento de processos de aquisição, tipos de atividades extra-sistema para complementação de estatísticas, tabela de Cutter, tabela de instituições, de localização de documentos, de motivos de baixa, de materiais especiais e de tipos de monografias. Adota o protocolo de comunicação entre computadores Z39.50, o formato MARC e a ISO 2709. Possui o módulo de legislação e apresenta uma visão única do sistema, com integração de módulos. Por trabalhar com o banco de dados textuais, BRS-Search, o tempo de resposta torna-se rápido e de fácil compreensão e utilização pelo usuário.

Observou-se no Geipot satisfação com o produto. Todas as funções da biblioteca estão automatizadas e em pleno funcionamento. O único problema constatado foi o atraso na entrega do projeto, em razão da mudança de plataforma tecnológica que ocorreu na instituição durante a fase de implantação da automação, sem prejuízo da qualidade no resultado final. A biblioteca não possuía nenhum dado para ser migrado ou convertido. Houve, de fato, o trabalho de implantação de todos os registros existentes em fichas catalográficas, para o que foi contratada a própria Via Ápia, que precisou de três meses para digitar e alimentar cerca de 18 mil registros bibliográficos.

No TSE, observou-se que houve certa insatisfação e até desgaste institucional no início da implantação, com problemas decorrentes da migração de dados do formato Cepal para o formato Marc. Porém, hoje os problemas es- 
tão plenamente solucionados.

\section{Ex- Libris, responsável pelo software Aleph}

A Ex-Libris é uma empresa ligada à Universidade Hebréia de Jerusalém, criada especificamente para comercializar o Automated Library Expandable Program (Aleph). Sua sede é em Jerusalém e no Brasil possui representação por um escritório em São Paulo, porém a sede para a América Latina encontra-se em Buenos Aires.

Adquirida a licença de uso, a casa matriz tem a responsabilidade de manter a atualização sem custo para o usuário. Após o primeiro ano, é feito contrato de manutenção. Quando da demonstração do produto, o técnico responsável não trabalhou com uma versão a exemplo dos demais, mas trouxe sua própria estação de trabaIho e acessou as bases de dados que utilizam o Aleph via Internet. A ExLibris conta com o apoio tecnológico da Universidade Hebréia de Jerusalém. Contudo, mantém em seu quadro de pessoal, técnicos especializados em sistemas de automação de bibliotecas e centros de documentação. A partir de 1986 começou a comercializar o sistema fora de Israel e atualmente possui como usuários no Brasil, a Rede de Bibliotecas da Universidade de São Paulo (USP), a Rede de Bibliotecas da Universidade do Estado de São Paulo (Unesp), a Biblioteca da Universidade de São Marcos-SP, a Biblioteca da Pontifícia Universidade Católica do Rio Grande do Sul-RS a Universidade de Campinas (Unicamp).

Por não ter, no momento, nenhuma instituição em Brasília que esteja operando com o Aleph, não foi possível verificar a satisfação do usuário. Entretanto, a equipe técnica da PR esteve em reunião com a Diretoria da Biblioteca do Senado Federal, que decidiu, após analisar vários sistemas, adotá-lo, sendo esta sua decisão compartilhada e aprovada pela equipe de analistas de sistemas do Centro de Informática e Processamento de Dados do Senado Federal (Prodasen). Até o momento, as negociações ocorreram em um clima bastante satisfatório e todas as dúvidas apresentadas pelo cliente foram plenamente atendidas. Esta op- ção é uma alternativa de atualizar a plataforma computacional utilizada pela Rede de Bibliotecas gerenciada pelo Prodasen. É um software do qual $60 \%$ de sua clientela constitui-se de bibliotecas universitárias.

O Aleph é um software desenhado especificamente para o gerenciamento de bibliotecas e centros de documentação e informação bibliográfica. É um sistema amigável e totalmente integrado. Todos os módulos, com exceção do banco de dados que gerencia o grupo de itens de fontes externasempréstimo entre bibliotecas -, possuem o mesmo banco de dados. O sistema é baseado em tabelas de parâmetros direcionadas pela concepção on site do sistema para aplicações específicas. Os módulos integrados do sistema incluem o On-line Public Access Catalog (OPAC), catalogação, aquisição, circulação, seriados, geração de relatórios e empréstimo entre bibliotecas.

Foi desenhado com a filosofia de flexibilidade máxima. Isto é atingido com o uso de um grupo de tabelas externas que podem ser concebidas de acordo com as necessidades de cada usuário e modificadas sempre que necessário. As mudanças são controladas pelos bibliotecários e podem ser realizadas a qualquer momento, não sendo necessário ter conhecimentos de programação de computadores. Desta forma, permite ao bibliotecário conceber o sistema de acordo com suas necessidades: definições bibliográficas, campos de pesquisa, geração de índices, exibição de telas, mensagens, grupos de usuários com privilégios variados e outros. A arquitetura é baseada no modelo cliente/ servidor de camadas múltiplas. A comunicação cliente/servidoré baseada em um modelo de transação embutido. Entretanto, servidores de aplicação do ALEPH mantêm conexões contínuas (time-out) com o banco de dados, para assegurar máxima performance. É adaptável aos mais diversos tipos de instituições: bibliotecas, museus, arquivos e centros de pesquisa, privilegiando o tratamento e recuperação de informações bibliográficas, museológicas e arquivísticas.

Trabalha bem tanto em pequenas ou grandes instituições com poucos ou muitos usuários. A capacidade do banco de dados varia de 100 mil a 9 miIhões de registros, suportando uma rede de bibliotecas com um ou mais servidores. Pode ser usado com registros bibliográficos em diversas línguas, e o idioma de conversação pode ser definido pelo usuário e alterado em qualquer momento da sessão. Possui interface desenvolvida para sistemas de imagem, texto, áudio e empréstimo. Trabalha em tempo real, sendo que inclusões, alterações e exclusões atualizam o banco de dados imediatamente. O registro bibliográfico inclui campos, indicadores e subcampos que correspondem aos padrões do LC Marc, UK Marc, Unimarc, Danmarc, Iber Marc. Como todas as tabelas possuem um padrão de parâmetros, outros padrões Marc podem ser facilmente definidos. É compatível com os protocolos de comunicação WWW e Z39.50.

\section{Modo Novo Consultoria e Informática Ltda., responsável pelo software Informa Biblioteca Eletrônica}

A Modo Novo é uma empresa oriunda da Contempory, tendo sido criada em 1997, com sede na cidade do Rio de Janeiro e sua atuação está voltada integralmente para a área de informatização de bibliotecas e centros de documentação, atendendo nacionalmente a todas as demandas recebidas. A equipe que desenvolveu o Informa é composta de profissionais universitários com mais de 10 anos de experiência, com formação em especialização em desenvolvimento de sistemas de informação. Sua sócia majoritária possui 14 anos no mercado de sistemas para bibliotecas. O software reflete os conhecimentos e experiências acumuladas pela equipe. $O$ Informa pode ser adquirido por rotinas ou 0 sistema total.

Possui como usuários as bibliotecas das seguintes instituições: 
Em São Paulo: Associação Paulista de Medicina, Ginásio Koelle, Pinheiro Neto Advogados, Sul América Seguros, Universidade Metodista, Fundação Jorge Duprat Figueiredo de Segurança e Medicina do Trabalho (Fundacentro), América Seguros e Previdência, Associação Educacional Presidente Kennedy, Associação Lemense de Educação e Cultura, Associação Valinhense de Educação e Cultura, Colégio São José de Bauru, Conselho Regional de Medicina, Instituto Superior de Comunicação Publicitária, Biblioteca Municipal Prof. Arthur Ricci de Camargo e Universidade São Francisco.

No Rio de Janeiro: Faculdade Cândido Mendes, Instituto de Filosofia e Ciências Sociais da Universidade Federal do Rio Janeiro, Assembléia Legislativa do Estado do Rio de Janeiro, Associação de Ensino Superior do Rio de Janeiro, Procuradoria Geral do Município do Rio de Janeiro, Centro de Estudos de Pessoal do Exército, Confederação Nacional do Comércio, Instituto Teológico Franciscano, Secretaria Municipal de Cultura, Sociedade Unificada de Ensino Superior Augusto Mota, Tribunal de Contas do Município.

No Espírito Santo: Colégio Cristo Rei, Companhia Siderúrgica de Tubarão, Aracruz Celulose e Sociedade Educacional do Espírito Santo.

No Rio Grande do Sul: Instituto Metodista de Educação e Cultura; em Brasília: Pinheiro Neto Advogados.

O Informa Biblioteca Eletrônica caracteriza-se por ser um software bem desenhado, com interface gráfica, encontrando-se ainda em fase de desenvolvimento e aperfeiçoamento de módulos para atender com maior segurança e completeza as funções de uma biblioteca.

Comporta uma biblioteca pequena que não pretenda trabalhar em rede. Sua capacidade de armazenamento e tratamento de dados, atualmente, gira em torno de 70 mil registros. Desenvolvido para trabalhar especificamente no ambiente Windows $(95,3.11$ e 3.1$)$, sua estrutura está dividida nas rotinas de controle de aquisições, de recuperação e cadastro de dados de publicações, de controle de periódicos, de controle de empréstimo, de controle de vocabulário e de controle de publicações jurídicas.

Conta ainda com o recurso de tabelas auxiliares de autores, assuntos, editores, usuários e as tabelas de esferas, espécies, órgãos, pronunciamentos e tipos de processos todas específicas para a área jurídica. Outras tabelas foram desenvolvidas como suporte ao uso do sistema: tabela de categorias de documentos, de curso/classificação, de curso/área/departamentos, de idiomas, de moedas, de origens da aquisição, de países, de qualificação, de status da aquisição, de stopword, de tipos de documento, de tipos de publicação, de tipos de teses e de unidades.

Com relação ao questionário enviado pela $\mathrm{PR}$, as respostas foram elaboradas e observou-se que o produto não atendia a algumas questões. Dessas, a mais importante é não trabalhar com a arquitetura cliente/servidor, fato que indicou não ser necessário realizar visitas junto aos usuários do sistema.

\section{Dins - Dados, Informação \& Serviços, responsável pelo software: Caribe}

A Dins - Dados, Informação \& Serviços -, recente no mercado, é uma empresa especializada em redes e sistemas de informação, com ênfase no desenvolvimento de sistemas para automação de bibliotecas e centros de documentação, arquivos e museus.

Seu produto básico é o Caribe. O principal acionista da Dins é oriundo da Fundação Getúlio Vargas, do Rio de Janeiro, e traz consigo a experiência de criação e implantação da Rede Bibliodata Calco. Propõe-se a realizar o diagnóstico e planejamento de unidades de informação, elaborar projetos para a implantação de sistemas de automação e ao desenvolvimento de softwares específicos. Não possui infra-estrutura de organização empresarial e faz uso de serviços terceirizados quando há necessidade de desenvolver ou atualizar parte do sistema.

O Caribe é um software desenvolvido para automação de bibliotecas e centros de documentação, totalmente compatível com os padrões nacionais e internacionais de registro bibliográfico, apresentando grande inovação, que é trabalhar com documentos arquivísticos, bibliográficos e museológicos.

Utiliza a arquitetura arquivo remoto e não cliente/servidor. Seu estágio atual está voltado mais para atender a bibliotecas de pequeno porte que não pretendam trabalhar em rede. Está configurado para atender às funções de catalogação/recuperação, empréstimo, periódicos e controle de coleção. O módulo de catalogação suporta qualquer tipo de documento. Pode redefinir todas as telas de entrada de dados, campos e subcampos, conforme o modelo de dados adotado pelo cliente. É compatível com o formato Marc.

O módulo de recuperação permite a consulta pelos índices de autor, título, assunto, série, entre outros. Possibilita a busca por palavras ou expressões booleanas, inseridas em qualquer campo indexado. $O$ de empréstimo está voltado ao controle de utilização do acervo e inclui cadastro de leitores e arquivo de circulação integrados às bases do sistema. Permite as funções para controle de uso local, empréstimo domiciliar, reservas, solicitação de empréstimo por rede, devolução, cobranças e estatísticas. A função cooperação permite a cópia seletiva de registros bibliográficos de outras bases de dados para uma base do sistema, desde que as bases de onde a informação é capturada esteja no formato do sistema Caribe ou em formatos de intercâmbio que possam ser convertidos: Marc, Calco ou Isis.

No módulo periódicos e controle de coleção, além das atividades normais desta função, o sistema realiza a atualização do Catálogo Coletivo Nacional de Periódicos (CCN), do Instituto Brasileiro de Informação em Ciência e Tecnologia (IBICT) e permite a digitalização dos sumários correntes 
para recuperação em rede. Não depende de produtos adicionais como gerenciadores de base de dados, reduzindo, conseqüentemente, custos e facilidades na implantação.

\section{DRV Informática, responsável pelo software: Biblio}

A DRV Informática é uma empresa sediada em Belo Horizonte-MG que representa, no Brasil, a empresa Text Information Systems (TIS), com sede em Berna-Suíça, proprietária do aplicativo Biblio. Ficou um pouco prejudicada a identificação das características básicas da empresa, pois não foi possível realizar a demonstração do produto pelo fornecedor e o questionário respondido não continha informações suficientes para esclarecimento das dúvidas.

De acordo com as informações constantes do questionário respondido, o Biblio é um aplicativo desenvolvido para execução em AS/400, no software ĺcaro, uma ferramenta que permite modificação e implementação de novas rotinas. Dentre os quesitos não preenchidos pelo software, os mais importantes dizem respeito a não possuir interface gráfica, não utilizar o formato Marc nos registros bibliográficos, não fazer leitura de código de barras, não possuir formato de visualização dos registros de acordo com a ABNT e AACR2. Constata-se, entretanto, que está desenvolvido em uma ferramenta com alta performance, grande capacidade de armazenamento de dados, porém sem contemplar alguns requisitos imprescindíveis ao processo de automação bibliográfica.

\section{Walda Antunes Consultorias/WA Corbi, responsável pelo software: ArcheS Lib}

A Walda Antunes Consultorias é uma empresa com sede em Brasília produtora do Software ArcheS Lib para gerenciamento de bibliotecas, desenvolvido com base na experiência de téc- nicos e consultores especializados em biblioteconomia, documentação e informática. É o único Centro de Treinamento Autorizado Borland, credenciado no Distrito Federal, denominado Borland VAR Authorized Education Center, e possui como usuários as seguintes instituições:

Em Brasília: Biblioteca Demonstrativa de Brasília, Biblioteca da Companhia de Água e Esgoto de Brasília (Caesb), Colégio Compacto, Colégio AD1, Centro Educacional Jesus Maria José. Em Santa Catarina: Delegacia do Ministério da Educação e do Desporto de Florianópolis/SC. No Rio de Janeiro: Casa da Leitura, Fundação do Livro Infantil e Juvenil. Na Bahia: Conselho Regional de Administração (CRA).

De acordo com o questionário respondido, verificou-se tratar de um produto novo no mercado, em estágio de desenvolvimento. Dos requisitos exigidos, - ArcheS Lib não realiza acesso à base de dados via browser Internet, não recupera bases de dados textuais, não trabalha com imagens, não faz controle de listas de sugestão, seleção, aquisição, reclamação e recebimento, não constrói remissivas para autores e assuntos. Procura, entretanto, privilegiar todas as etapas do ciclo documental, adota os padrões internacionais de descrição bibliográfica, o que garantirá a completeza do sistema tão logo todos os módulos estejam em pleno funcionamento.

\section{CONCLUSÃO}

Automatizar os procedimentos de trabalho de bibliotecas ou centros de documentação é uma tarefa que apresenta certa complexidade, por ser um processo que foge aos padrões habituais, a exemplo do controle de estoques, folhas de pagamento, contabilidade e outros. Ainda, porque as tarefas relacionadas à biblioteconomia e documentação são diferenciadas e detalhadas a ponto de dificultarem soluções globais e lineares.

Isto quer dizer que não são muitos os profissionais de processamento de dados que têm desembaraço neste tipo de aplicação, o que gera certo desconforto e dificuldade para o bibliotecário dialogar com o analista de sistemas, tanto para expor suas necessidades quanto para ouvir soluções compatíveis com seu problema. Com o advento das tecnologias de informação acompanhado do processo de globalização, o mercado está a exigir profissionais mais flexíveis, dinâmicos, ágeis, criativos e que consigam trabalhar com equipes multidisciplinares.

Se antes o bibliotecário atuava juntamente com o analista de sistemas, hoje, mesmo com a facilidade apresentada pela microinformática facilitando o uso das tecnologias de informação e ampliando a interação com o usuário, não fica prejudicada a necessidade dessa parceria, mesmo porque essas tecnologias facilitaram o processo, mas não eliminaram os conhecimentos específicos que cada um traz como resultado de sua formação profissional. Assim, a escolha de um software é tarefa cooperativa, integrada e participativa entre esses profissionais e constitui um dos grandes desafios para as bibliotecas e unidades de documentação e informação bibliográfica.

No decorrer deste trabalho, observouse que alguns aspectos adquiriram relevância e, à guisa de conclusão e como contribuição deste estudo, orientando analistas e bibliotecários, ficaram ressaltados:

a) é inviável, hoje, adotar uma solução caseira para o processo de automação de bibliotecas, pois o mercado oferece bons produtos. Basta a instituição procurá-los na perspectiva de qual melhor 
se adaptará às suas características;

b) os softwares devem privilegiar o compartilhamento de dados e intercâmbio de informações adotando os formatos e padrões específicos ao intercâmbio de dados bibliográficos;

c) o processo de automação de bibliotecas e centros de documentação exige um projeto de implantação elaborado numa parceria fabricante do produto e usuário;

d) a Conversão Retrospectiva (CR) é considerado um trabalho intelectual e como tal deve merecer um projeto específico;

e) é importante que o software escoIhido esteja pronto, testado, atendendo o nível de satisfação exigido pelos usuários;

f) qualquer software a ser adquirido só terá a licença de uso e não o produto em si, e a atualização de versões será feita mediante contrato de manutenção;

g) o software deve ser avaliado não só sob seus aspectos metodológicos e tecnológicos, mas também quanto à capacidade de a empresa fornecedora do produto responsabilizar-se pelo treinamento, garantir suporte técnico em tempo hábil adequado às demandas do usuário, instalar e realizar os testes necessários ao perfeito funcionamento do sistema, apresentar documentação atualizada tanto do produto quanto a que garanta idoneidade da empresa, bem como sua capacidade de realizar a conversão retrospectiva.

Com base nessas considerações e na pontuação obtida na análise dos requisitos imprescindíveis e desejáveis, a equipe identificou que os softwares OrtoDocs, ALEPH e Thesaurus atendiam plenamente às exigências da PR, sendo compatíveis com sua estrutura objetivos e funções organizacionais, bem como com o parque e recursos computacionais existentes.

Aprovado o relatório final pela Diretoria, foi o mesmo encaminhado à unidade competente, que, atendendo às exigências legais de aquisição de bens e contratação de serviços na Administração Pública Federal, segundo a Lei de Licitações, e tendo por base as características técnicas identificadas neste estudo, realizou procedimento licitatório público, tendo sido vencedor o software Thesaurus, da Via Ápia.

Como palavras finais, buscamos em Davenport ${ }^{3}$ a essência do que bibliotecários e analistas de sistemas procuram refletir no momento de escolha e implantação da automação de suas unidades de informação bibliográfica: "caberá ao gerente criar estratégias quanto aos tipos de informações que devem ser focalizadas, as atividades a enfatizar e a maneira como a informa- ção poderá ajudar a organização a alcançar seus objetivos." 


\section{REFERÊNCIAS BIBLIOGRÁFICAS}

1. RELATÓRIO da reunião técnica de bibliotecários da Justiça Federal. Brasília: Conselho da Justiça Federal, 1997. 6p.

2. HEEMANN, Vivian. Mudança de hábito; impacto das novas tecnologias na qualificação do profissional bibliotecário e no MAÇÃO EM BIBLIOTECAS E CENTROS

\section{Automation of libraries and documentation centers: a evaluation process of softwares}

\begin{abstract}
s
The market of production and make up of software for library automation has shown a great impulse in the last ten years. Choosing a software today, is more than just choosing a technological tool to implement services for libraries. It represents the introduction of a new philosophy of work, new behavior and new informational values. This work shows the result of studies performed for the choice of a software for automation of libraries in the Presidencia da República. Contribute of professionals and scholars in the field is included in the review of literature, in the analysis of each product and identification of desirable and necessary requirements that the software should offer to the process of automation of libraries and documentation centers.
\end{abstract}

\section{Keywords}

Automation of libraries; Library software; Informatics applied to libraries. uso final. In: SEMINÁRIO SOBRE AUTODE DOCUMENTAÇÃO, 5., 1994, São José dos Campos. Anais... São José dos Campos: UNIVAP, 1994. p. 172-176.

3. DAVENPORT, Thomas H. Ecologia da Informação: por que só a tecnologia não basta para o sucesso na era da informação. Tradução por Bernadette Siqueira Abrão. São Paulo: Futura, 1998. 316p. Tradução de Information ecology.

4. COSTA, Marília M. Damiani, HEEMANN, Vivian. Automação em bibliotecas: o uso de novas tecnologias. In: SEMINÁRIO NACIONAL DE BIBLIOTECAS UNIVERSITÁRIAS, 8, 1994, Campinas. Anais... Campinas: UNICAMP, 1995. p. 325-337.

5. MARTINELLI, Ada Tereza Spino. A base de dados bibliográficos de acervo como suporte para o processo de automação: uma experiência na UNESP. IN: SEMINÁRIO NACIONAL DE BIBLIOTECAS UNIVERSITÁRIAS, 10., 1998, Fortaleza. Anais eletrônicos. File:///c|/netscape/ anais/trabalho/sessão/abaseded.htm

6. KRZYZANOWSKI, Rosaly Favero, IMPERATRIZ, Inês Maria de Morais, ROSETTO, Macia. Subsídios para análise, seleção $e$ aquisição de software para gerenciamento de bibliotecas: experiência do sistema integrado de bibliotecas da USP. São Paulo: Universidade de São Paulo, 1996 (Cadernos de Estudos, 5).

\section{Adelaide Ramos e Côrte}

Especialista em administração de sistemas de informação pela Associação dos Bibliotecários do Distrito Federal e Fundação Centro de Formação do Servidor Público (Funcep) e mestre em biblioteconomia e documentação pela Universidade de Brasília.

e-mail: adelaide@persocom.com.br

\section{lêda Muniz de Almeida}

Chefe da Biblioteca do Palácio do Planalto.

e-mail: iedamuni@planalto.gov.br

\section{Ana Emília Pellegrini}

Bibliotecária da Secretaria de Assuntos Estratégicos da Presidência da República.

e-mail: ana@cepesc.gov.br

\section{Ildeu Ordini Lopes}

Analista de sistemas da Subsecretaria de Inteligência da Casa Militar da Presidência da República.

e-mail: ilopes@cin-sci.gov.br

\section{José Carlos Saenger}

Gerente do Centro de Documentação e Referência da Secretaria de Assuntos Estratégicos da Presidência da República.

e-mail: saenger@sae.gov.br NÁRIO NACIONAL DE BIBLIOTECAS UNIVERSITÁRIAS, 10., 1998, Fortaleza. Anais eletrônicos. File:///c|/netscape/ anais/trabalho/comum/situação.htm

8. INFORMATION retrieval (Z39.50): application service definition and protocol specification. [s.I.]: NISO, 1995. 155p.

9. AVRAN, Meuriette D. El servicio MARC: su historia y sus consecuencias: Tradução por Alfonso Castoño. Mexico: Biblioteca Benjamin Franklin, 1976. 43p. Tradução de: MARC: its histories and implications.

10. FERREIRA, Margarida M. Estudo do formato para registro bibliográfico MARC. São Paulo: Associação Paulista de Bibliotecas, 1998. (Ensaios APB, 52).

11. NUNES, Vera Vilene Ferreina, SILVA, Gisélia Fereira da, RIBEIRO, Rejane Maria Rosa. Uma alternativa de sucesso para integral informatização do sistema de bibliotecas da Universidade Estadual de Feira de Santana - BA. IN: SEMINÁRIO NACIONAL DE BIBLIOTECAS UNIVERSITÁRIAS, 10., 1998, Fortaleza. Anais eletrônicos. File:///c//netscape/anais/trabaIho/paineis/umaalter.htm

\section{Maria Bernadete Pereira Esmeraldo}

Analista de sistemas da Subsecretaria de Análise e Avaliação da Secretaria de Assuntos Estratégicos da Presidência da República.

e-mail: bernadet@sae.gov.br

\section{Maria Cristina Moraes Pereira}

Chefe da Biblioteca e Memorial de Inteligência da Subsecretaria de Inteligência da Casa Militar da Presidência da República.

\section{Rosana Rika Matsuuchi Coelho Ferreira}

Coordenadora de produto da Gerência de Sistemas da Caixa Econômica Federal, em Brasília, DF.

\section{Wilma Garrido do Lago}

Bibliotecária da Biblioteca do Palácio do Planalto.

e-mail:wilma@planalto.gov.br 